\title{
ANAPHYLAXIS IN PREGNANCY: A CASE REPORT
}

Tavares F. ${ }^{1}$, Dias A. ${ }^{1}$, Pires AC. ${ }^{1}$, Matias C. ${ }^{1}$

${ }^{1}$ Anesthesiology Department, Centro Hospitalar Tâmega e Sousa EPE

\section{BACKGROUND}

Anaphylaxis is currently defined as a serious allergic reaction that is rapid in onset and might cause death. Data regarding prevalence among pregnant women is limited, with an estimated prevalence near or at the time of delivery reported as 2.7 cases of anaphylaxis per 100.000 deliveries. Furthermore, the risk of cesarean delivery in anaphylactic women is high (74\%)..$^{1}$ During the first 3 trimesters, aetiologies are similar to those in non-pregnant women.

\section{CASE REPORT}

A 19-year-old pregnant woman (30 weeks' gestation) presented to the emergency service complaining of back pain and flank tenderness. She had a history of inadequate prenatal care and multiple urinary tract infections, with hospitalization at 28 weeks of pregnancy for pyelonephritis and treatment achieved with intravenous cefuroxime. After careful examination, the patient was diagnosed with an urinary tract infection. It was decided to hospitalize the patient for surveilance and antibiotic therapy with cefoxitine.

Within 2 minutes after first
dose of antibiotic the patient
developed
- Facial Sweeling
- Dyspnoea $\rightarrow$ SpO2 92\%
- Severe hypotension

It was administred:

- Hydrocortisone 200mg IV

- Clemastine 2mg IV

- Adrenaline $1 \mathrm{mg}$ IM (mid-outer thigh)

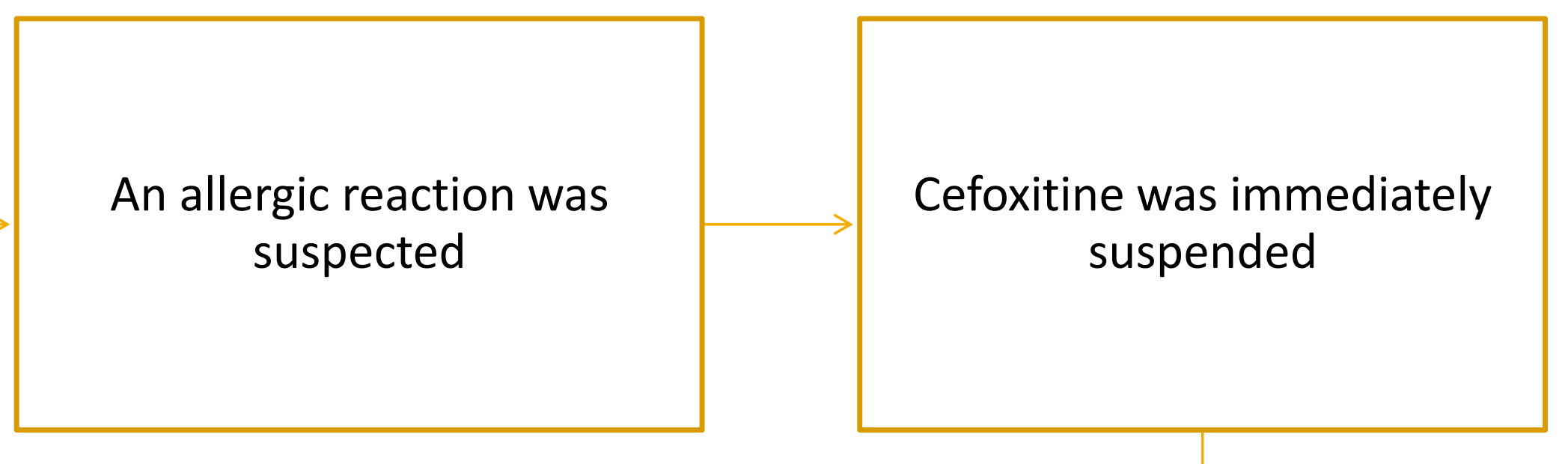

Clinical improvement was rapidly noted and:

- Oxygen saturation $98 \%$ (supplemental oxygen $6 \mathrm{~L} / \mathrm{min}$ )

- Blood pressure $92 / 57 \mathrm{mmHg}$

- Heart rate $53 \mathrm{bpm}$

\section{FOLLOW-UP}

Throughout the whole episode the obstetric evaluation was unremarkable and fetal sonographic examination was reported as normal. A caesarean delivery was not undertaken. The patient's hospital course was uneventful and she was discharged home 5 days later.

\section{DISCUSSION}

Anaphylaxis during pregnancy, labour and delivery is rare and can be catastrophic for the mother and, especially, the newborn. In cases of anaphylaxis during pregnancy, it's important that both the mother and the fetus are treated, and continuous vigilance of fetal well-being for $48-72 \mathrm{~h}$ is maintained, in order to identify precocious signs of fetal distress.

\section{LEARNING POINTS}

Management of anaphylaxis in pregnant women is similar to that of non-pregnant ones. Treatment should start immediately in order to prevent further development of the anaphylaxis

\section{reaction and fetal neurological deficiency.}

\section{References:}

1. Mulla ZD, Ebrahim MS, Gonzalez JL. Anaphylaxis in the obstetric patient: analysis of a statewide hospital discharge database. Ann Allergy Asthma Immunol 2010; 104:55-9 